\title{
COMPARISON OF ANTICIPATORY GLANCING AND RISK MITIGATION OF NOVICE DRIVERS AND EXEMPLARY DRIVERS WHEN APPROACHING CURVES
}

\author{
Jeffrey W. Muttart, Donald L. Fisher, Alexander P. Pollatsek \& Jenna Marquard \\ University of Massachusetts-Amherst \\ Amherst, Massachusetts, USA \\ Email: muttartj@gmail.com
}

\begin{abstract}
Summary: Novice drivers are overrepresented in run-off-the-road crashes. Indeed, the previous literature demonstrates that novice drivers are less likely to anticipate hazards or maintain attention to the forward roadway and as a result fail to mitigate hazards by slowing. This research was an effort to compare the linked hazard anticipation and hazard mitigation behaviors of novice drivers with exemplary experienced drivers at curves, locations that are known to have a greater crash risk. Each driver navigated three drives in a driving simulator, one of which included a moderate curve left and one of which included a tightening curve right. Experienced drivers made more anticipatory glances and began slowing significantly earlier in the curves than did novice drivers. However, novice drivers who anticipated hazards were much more likely to also mitigate the hazard. The use of these results in a PC-based driver hazard mitigation training program will be discussed.
\end{abstract}

\section{INTRODUCTION: NOVICE DRIVERS ARE OVERREPRESENTED IN RUN-OFF- ROAD [ROR] AND LEFT TURNING CRASHES}

In 2010 drivers ages 16 and 17 were approximately 50\% more likely to die in a crash than 35-44 year old drivers (FARS query, 2012). Drivers age 16 and 17 were nearly 100\% more likely to die in a crash where the first harmful event involved striking an object off the road or a rollover (FARS Query, US DOT, 2012). According to Glennon et al., (1983) 76\% of all crashes on a curve involve a single vehicle. Moreover, the accident rate on curves was three times that of straight road segments. The research below focuses on novice and experienced drivers' behaviors at curves.

The root cause of many single vehicles crashes at curves appears to stem from speed selection before entering the curve. In many single-vehicles crashes, drivers under steered, the likely result of braking sharply (Zegeer, et al, 1990) or over steering (Glennon, et al., 1983; Maeda, et al. 1977), producing a turn that was sharper than the highway curve and further reducing the available friction. Over steering and under steering occur after cresting the curve. Anticipating and slowing before the curve is the optimal solution to both problems (Glennon et al, 1983; Mikolajetz, 2009). Glennon et al. (1983) referred to the region three seconds before the curve as the critical region of operations. In the critical region, drivers should begin to adjust both their speed and path. Such adjustments were particularly large on sharper curves.

In order to determine why novice drivers might have a higher crash rate on curves than experienced drivers, it is useful to differentiate between hazard anticipation and hazard mitigation. In general, novice drivers were more likely to fail to anticipate hazards, particularly when the hazard might be obscured (Pollatsek et al., 2006). Novice drivers are also less likely to 
mitigate hazards. For example, in a driving simulator study, when bushes obscured a stop sign at the end of a curve to the right the novice drivers braked much harder on average when approaching the stop sign than did the experienced drivers despite a "stop ahead" sign (Fisher et al., 2002). Unfortunately, the above research cannot be used to determine whether novice drivers failed to anticipate the hazard or, instead, anticipated the hazard but failed to mitigate it.

The research reported here takes a step beyond the above studies and attempts to determine whether hazard anticipation is a factor in preemptive (or preparatory) speed loss and changes in lane position. Briefly, hazard mitigation behaviors at curves are possible only if the driver correctly anticipates the curvature of the roadway. Land and Lee (1994; also see Suh, et al., 2006) suggested that drivers' glances might be used to determine how well drivers can predict the curvature in the road ahead. Clearly, a driver who fails to look downstream is more likely to be surprised by the events that come next. Thus, novice drivers who fail to glance ahead are very likely to be ill prepared for upcoming events. The specific preparatory response here would be to slow significantly before the curve. In this research, an eye tracker is used to compare the glances toward the curve of novice and experienced drivers.

There were two curve types that were of greatest interest and were examined. Left curves have been cited as being less of a threat with less speed loss (Mikolajetz, et al, 2009). Right curves, longer curves and curves with smaller radii have been associated with greater crash risk (Anderson, et al., 2000; Glennon, et al., 1983). This research examined driver glance and speed mitigation behaviors for gradual curves left and a longer tightening curve to the right.

\section{METHOD}

The goal of this research was to identify the hazard anticipation and risk mitigation tactics used by experienced drivers which were not used by novice drivers at curves in a driving simulator. Drivers in both age groups navigated through a simulated virtual world for approximately 36 minutes. During the drive, they negotiated three curves. Curves are known to be a common location for run-off-road (ROR) crashes. Each driver negotiated a number of scenarios, which were potentially hazardous, including a sharp curve to the right and a moderate curve to the left. A hazard appeared in one of the curves for which the driver needed to take action in order to avoid a crash.

It was hypothesized that experienced drivers would be more likely to make anticipatory glances toward the far extent of the sightline in the area of a potential hazard. Furthermore, conditional on a glance being made toward the area that contained information on a potential hazard, it was hypothesized that experienced and novice drivers would be equally likely to slow and thus neutralize the potential hazard so it would not develop into an immediate hazard. Lastly, it was hypothesized that novice drivers would fail to respond (slow) more often than experienced drivers and thus face more crash and near crash situations.

This research was a first step toward identifying the skills that novice drivers must learn to drive safely. It was imperative to compare these novice drivers to exemplary drivers with no crash history, not simply experienced drivers who may or may not be proper role models. Every effort was made to recruit exemplary drivers. 


\section{Participants}

The eighteen novice drivers (nine female) were recruited through youth organizations and local driving schools. The novice drivers averaged 17.0 years old and ranged from 16 to 18; they had been licensed for an average of 2.6 months.

The eighteen experienced drivers (six female) were 26 to 61 years old. Each of them had been licensed for at least ten years with no at-fault crashes, or violations in that time and drove at least 20,000 kilometers per year. The average experienced driver was licensed 29.4 years and was 45.8 years old.

\section{Procedure}

After a four-minute practice drive, participants drove for approximately 36 minutes in a virtual environment. The experimental drives consisted of a number of different road geometries and intersections, including a gentle curve left and a tight radius curve right. If the driver failed to slow for the curve right, it became difficult to control the vehicle through the tightening turn.

\section{Equipment and Measures}

A fixed-based driving simulator in the Arbella Insurance Human Performance Laboratory at the University of Massachusetts Amherst was utilized for this study. The Real-time Technologies simulator makes use of a Saturn sedan. The forward driving scene was displayed across three screens that encompass a visual horizontal field of 150 degrees and a vertical field of 30 degrees. The ASL MobileEye eye tracker was employed to monitor eye movements of the driver. In the video that was reconstructed from the eye tracker, a crosshair representing the direction of the driver's gaze was superimposed onto the forward scene view. Among other things, this allowed one to determine which locations drivers fixated in the virtual world.

The dependent measures include the fixation location, lane position, and velocity. They were recorded continuously throughout the drive. However, they are reported below only as averages for each second for the ten seconds prior to the apex of the curve. Derived measures during each of the one second epochs include glances to the far extent of a curve, crashes, and target speed. Eye glance location and crashes were determined by trained blind scorers for each epoch. A crash was identified by the blind scorers when a driver struck another vehicle or traveled entirely off the road. A far extent glance was defined as a glance that cut across the inside of the curve, not simply to the inside of the curve, but at least three degrees from ahead and toward the road ahead. The target speed was also computed in each epoch. The target speed (depicted in Equation 1) is the present speed $\left(\mathrm{S}_{\mathrm{o}}\right)$ minus the speed loss in the previous second $\left(\mathrm{S}_{\mathrm{o}-1}\right)$ projected forward in time to the location of the curve ( $t t i$ - time to incident location):

$$
S_{\text {Target }}=S_{o}-t t i\left(\Delta S_{o-1}\right) \text {. }
$$




\section{RESULTS}

This research examined hazard anticipation and hazard mitigation behaviors of novice and exemplary experienced drivers at two curves, a routine curve left and a long tightening curve to the right. According to the model proposed by Bonneson and Pratt (2009), most drivers would reduce their speed by $10 \mathrm{~km} / \mathrm{h}$ on the curve left and greater than $32 \mathrm{~km} / \mathrm{h}$ on the curve right that were simulated in this study. Using the Bonneson model as a benchmark, we compared the speed loss and glance behaviors of the experienced and novice drivers. The speed limit was $40 \mathrm{mph}$ $(64 \mathrm{~km} / \mathrm{h})$. Given the expected speed loss, a target speed of $32 \mathrm{~km} / \mathrm{h}$ was utilized for the sharp curve right and a target speed of $54 \mathrm{~km} / \mathrm{h}$ was utilized for the moderate curve left.

\section{Aggregate Glance, Braking and Slowing Behaviors}

When approaching a sharp curve to the right, the experienced drivers were significantly more likely to make a glance to the far extent when five and six seconds before the curve [t (35) $>2.12 ; \mathrm{P}<0.05$ for both epochs] (see the red lines in

Figure 1; experienced drivers are the solid lines, novice drivers the dashed lines). Two seconds later (three seconds before the curve), the experienced drivers were significantly more likely to slow to the target speed of $32 \mathrm{~km} / \mathrm{h}$ (black lines in Figure 1) [t $(35)=2.28 ; \mathrm{P}=0.03$ ]. Overall, $20 \%$ fewer novice drivers glanced toward the far extent when four to eight seconds before the curve. Also, 20\% fewer novices slowed to the $32 \mathrm{~km} / \mathrm{h}$ target speed. Lastly, experienced drivers selected a lane position that was much farther toward the outside of the curve (near the centerline and left of the center of the lane) when two seconds before the curve (blue lines in Figure 1) [ $t$ $(35)=2.11 ; \mathrm{P}=0.04]$. Other than when stated, experienced drivers were more likely to glance to the far extent, more likely to slow to the target speed of $32 \mathrm{~km} / \mathrm{h}$, and more likely to select optimal lane positions in each second before the curve; however, the differences were not generally significant.

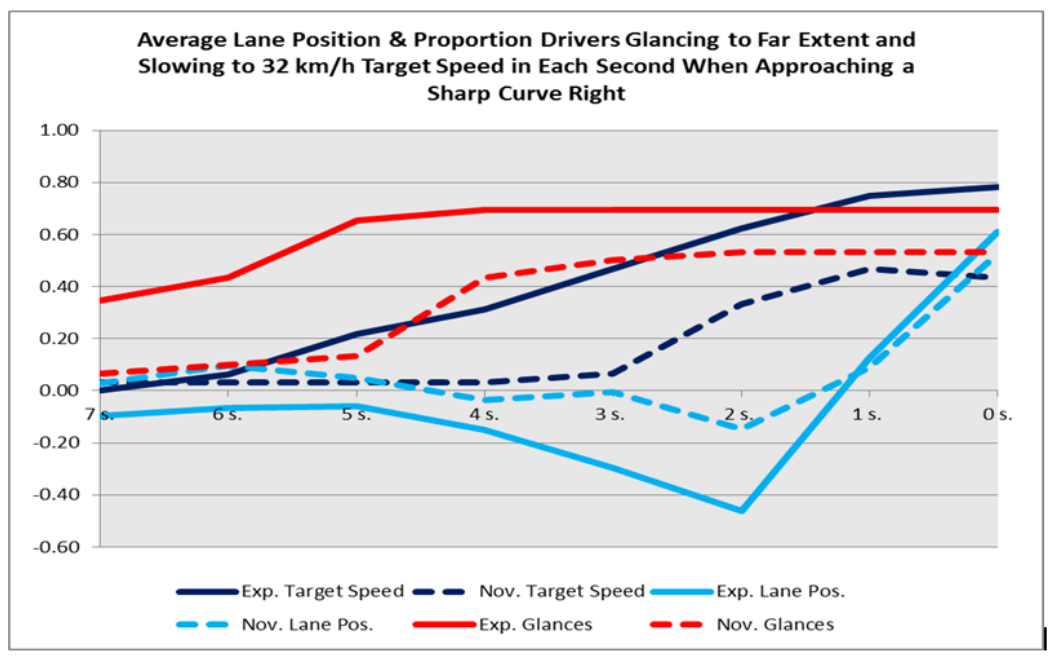

Figure 1. Glancing, slowing, and average lane position of experienced and novice drivers when approaching a sharp curve to the right [Red Lines: Proportion of drivers who glance to the far extent right. Black Lines:

Proportion of drivers who slowed to the target speed of $32 \mathrm{~km} / \mathrm{h}(20 \mathrm{mph})$. Blue Lines: Average lane position of drivers when approaching the sharp curve to the right (negative is left). Each time represents the time before the curve.]

At the curve left, more experienced drivers (56\%) glanced toward the far extent than did novice drivers $(25 \%)$ across all epochs $[\mathrm{t}(35)=2.00 ; \mathrm{P}=0.05)$. Related to mitigation behaviors, 
experienced drivers were significantly more likely to slow to target speed when three, five and seconds before the curve [t (35) $>2.23$; $\mathrm{P}<0.04$ for all three epochs]. Furthermore, experienced drivers were significantly more likely to be positioned to the outside of the curve when five and six seconds before the curve [ $\mathrm{t}(35)>2.77 ; \mathrm{P}<0.02$ for both epochs], and to be to the inside of the curve (left of center of the lane) when within one second of the curve $[\mathrm{t}(35)=4.24 ; \mathrm{P}=$ 0.00].

\section{Conditional Braking and Slowing and Crashes}

We compared the conditional outcomes in two ways. First, we looked at the percentage of drivers who looked to the far extent and slowed to target speed, given that they crashed. Second we looked at the percentage of driver who slowed to target speed, given that they glanced to the far extent.

Two experienced drivers and six novice drivers crashed at the sharp right curve location. Of those who glanced to the far extent and slowed to the target speed of $32 \mathrm{~km} / \mathrm{h}$, no experienced driver crashed (0 out of 9 ). Two of the nine experienced drivers crashed after failing to both glance and slow. Of the six novice drivers that both glanced and slowed, only one crashed. Conversely, of those who did not both glance and slow, five of twelve crashed. No drivers crashed at the more moderate curve left.

Next consider the slowing of experienced and novice drivers that glanced to the far extent when five to eight seconds before the sharp curve right. Of those who glanced, experienced drivers were more likely to slow to the target speed of $20 \mathrm{mph}(90 \%)$ than novice drivers (67\%). The percentage of novice drivers that slowed after failing to glance dropped to $47 \%$. At the curve left, experienced drivers that glanced to the far extent were more likely to slow to the target speed (55\%) than novice drivers (44\%). The percentage of novice drivers that slowed after failing to glance to the far extent dropped to 37\%. These relationships did not reach significance, which was primarily due to the impoverished numbers of novice drivers glancing to the far extent.

\section{DISCUSSION}

Novice drivers are at increased risk for run-off-the road crashes, many of which occur at curves. The question we asked was "Why?" First, consider the aggregate results. They suggest that novice drivers' failure to anticipate an upcoming curve was a major part of why they fail to reduce their speed appropriately before entering a curve. A large percentage of the experienced drivers glanced towards the far extent and across the curve left and curve right well before the apex, much as other researchers have reported (Land and Lee, 1994; Suh et al., 2006). Also, experienced drivers reduced their speed by the amount predicted by the Mikolajetz or Bonneson speed loss models. By comparison, novice drivers showed degraded hazard anticipation skills as predicted by Fisher et al. (2008), with the differences between the novice and experienced drivers being most pronounced as the crash risk of the curve increased.

Second, consider the comparison of novice and experienced drivers based on glancing and slowing as a conditioning event. Of the six novice drivers who crashed, only one glanced to the far extent and slowed before the sharp curve. Of the two experienced drivers that crashed, 
neither both glanced and slowed. Of the twelve novice drivers that did not crash, five both glanced and slowed. Yet of the experienced drivers that did not crash, $100 \%$ both glanced and slowed. It is clear that among experienced drivers, the likelihood of crashing is larger if one was did not both glance and slow before the curve than if one did both glance and slow. Among these drivers the likelihood of crashing appears not to depend on whether the driver did or did not both glance and slow before the curve.

Third, consider the comparison of novice and experienced drivers based on anticipatory glances five or more seconds before the apex of a curve as the conditioning event. It is clear from the results that slowing is associated with glancing: the likelihood of a driver slowing, whether novice or experienced, was higher given that the driver had glanced to the far extent. And it is clear that experience has a role: the likelihood that a driver slows, given that he or she has glanced, is higher for experienced drivers than it is for novice drivers. This answers the question set forth at the beginning. In particular, even when novice drivers notice that a curve is ahead (as evidenced by a glance to the far extent); they were less likely to slow (67\%) than experienced drivers (90\%).

There are two remaining issues to discuss. First, it is understood that a fixed-based driving simulator cannot replicate the feel that a driver has when negotiating a curve. However, this research addressed driver anticipation (glances) and pre-curve responses (target speeds) before lateral g-forces come into play.

Finally, one can ask whether training might be able to decrease run-off-road crashes. Given that failures of hazard anticipation were clearly implicated as a major cause of ROR crashes for novice drivers and given that hazard anticipation training has proven to have effects both on a driving simulator (Pollatsek et al., 2006) and in the field (Pradhan et al., 2006), effects that can last up to a year on the open road (Taylor et al., 2011), it would appear that it should be possible to train novice drivers to anticipate the hazards that curves present. As seen in this study, it is also the case that novice drivers did not slow enough (mitigate the hazard appropriately) even when they anticipate that hazard (glance at the hazard). Studies regarding the effects of training programs that target hazard mitigation behaviors are few and far between, but those that exist suggest that novice drivers can be trained to slow appropriately if they anticipate a given hazard (Fisher et al., 2002; Muttart, 2013).

\section{ACKNOWLEDGMENTS}

Portions of this research were funded by grants from the National Institutes of Health (1R01HD057153-01), the National Science Foundation (Equipment Grant SBR 9413733 for the partial acquisition of the driving simulator) and the Arbella Insurance Charitable Foundation.

\section{REFERENCES}

Anderson, I. B., Krammes, R. A. (2000). Speed reduction as a surrogate for accident experience at horizontal curves on rural two-lane roads, Transportation Research Record 1701, Washington, DC: Transportation Research Board.

Bonneson, J. A., Pratt, M. P. (2009). A model for predicting speed along horizontal curves on two-lane highways, Paper No. 09-1419, Washington, DC: Transportation Research Board. 
Fatal Accident Reporting System [FARS]. (2012). (National Highway Traffic Safety Administration) Retrieved November 12, 2012, from http://www.nhtsa.gov/people/ncsa/fars.html

Fisher, D. L. (2008). Evaluation of PC-Based Novice Driver Risk Awareness DOT HS 810926. Washington, DC: National Highway Traffic Safety Administration.

Fisher, D. L., Laurie, N. E., Glaser, R., Connerney, K., Pollatsek, A., Duffy, S. A. and Brock, J. (2002). The use of an advanced driving simulator to evaluate the effects of training and experience on drivers' behavior in risky traffic scenarios. Human Factors, 44, pp. 287-302.

Glennon, J. C., Neuman, T. R., Leisch, J. T. (1983). Safety and operational considerations for design of rural highway curves, (DOT - FH - 11 - 9575). McLean, VA: Federal Highway Administration.

Land, M. F., \& Lee, D. N. (1994). Where we look when we steer, Nature, 369(6483), 742-744.

Maeda, T., Irie, N., Hidaka, K., Nishimura, H. (1977). Performance of driver-vehicle system in emergency avoidance, (Technical paper 770130). Warrendale, PA; Society of Automotive Engineers.

Mikolajetz, A., Henning, M. J., Tenzer, A., Zobel, R., Krems, J. F., Petzoldt, T. (2009). Curve negotiation: identifying driver behavior around curves with the driver performance database, Proceedings of the fifth International Driving Symposium on Human Factors in Driver Assessment, Training and Vehicle Design, 391 - 397.

Muttart, J. W. (2013). Identifying hazard mitigation behaviors that lead to differences in the crash risk between experienced and novice drivers. (Doctoral Dissertation). University of Massachusetts-Amherst.

Pollatsek, A., Narayanaan, V., Pradhan, A, Fisher, D. L. (2006). Using Eye Movements to Evaluate a PC-Based Risk Awareness and Perception Training Program on a Driving Simulator. Human Factors: The Journal of the Human Factors and Ergonomics Society. 48, 447-464.

Pradhan, A. K., Fisher, D. L., Pollatsek, A. (2006). Risk Perception Training for Novice Drivers: Evaluating Duration of Effects on a Driving Simulator. Transportation Research Record, 1969, 58-64.

Suh, W., P. Park, Y-C, Park, C. H.and Chon, K. S. (2006). Relationship between Speed, Lateral Placement, and Drivers’ Eye Movement at Two-Lane Rural Highways, Journal of Transportation Engineering, 132, 649-653.

Taylor, T., Masserang, K., Divekar, G., Samuel, S., Muttart, J., Pollatsek, A., Fisher, D. L., (2011). Long-Term Effects of Hazard Anticipation Training on Novice Drivers Measured on the Open Road, 6th International Driving Symposium on Human Factors in Driver Assessment, Training, and Vehicle Design, Olympic Valley, CA.

Zegeer, C., Stewart, R., Reinfurt, D., Council, F.M., Neuman, T., Hamilton, E., Miller, T., and Hunter, W. (1990). Cost Effective Geometric Improvements For Safety Upgrading of Horizontal Curves. Publication No. FHWA-RD-90-021, University of North Carolina, Highway Safety Research Center, Chapel Hill, NC. 